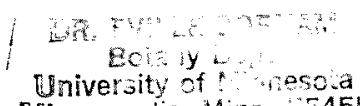

University of nesoca

Minnearis, Min -345

(Reprinted from Nature, Vol. 181, pp. 1523-1524, May 31, 1958)
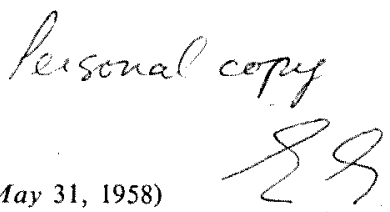

\title{
Accumulation of Radioactive Fall-out by Plants in the English Lake District
}

Turs communication reports an exploratory study of radioactivity in natural and cultivated vegetation. Thirty-five species of angiosperms and mosses, representative of a wide range of non-calcareous woodland, bog and fen habitats, were collected, and twenty samples of roots and tops from seven species of cultivated vegetables, near Windermere during early 1958. For a wider view, nineteen collections of the bog moss Sphagnum papillosum were made in

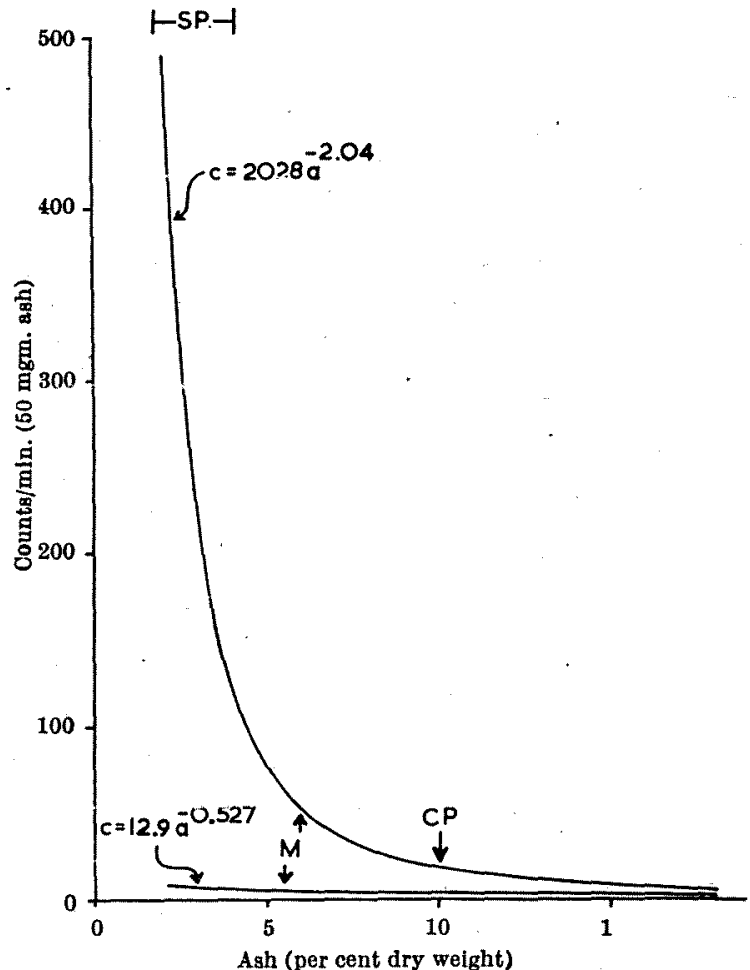

Fig. 1. The relation between radioactivity of plant ash and the agh content of the species. The upper curve represents samples taken in 1958; the lower, herbarium specimens collected prior to 1947. M ghows the generallog means, $C P$ the mean ash content of cultivated vegetables, and $S P$ the range of ash in Sphagnum papillosum. In the equations $c$ represents counts per min. and $a$ ash percentage 


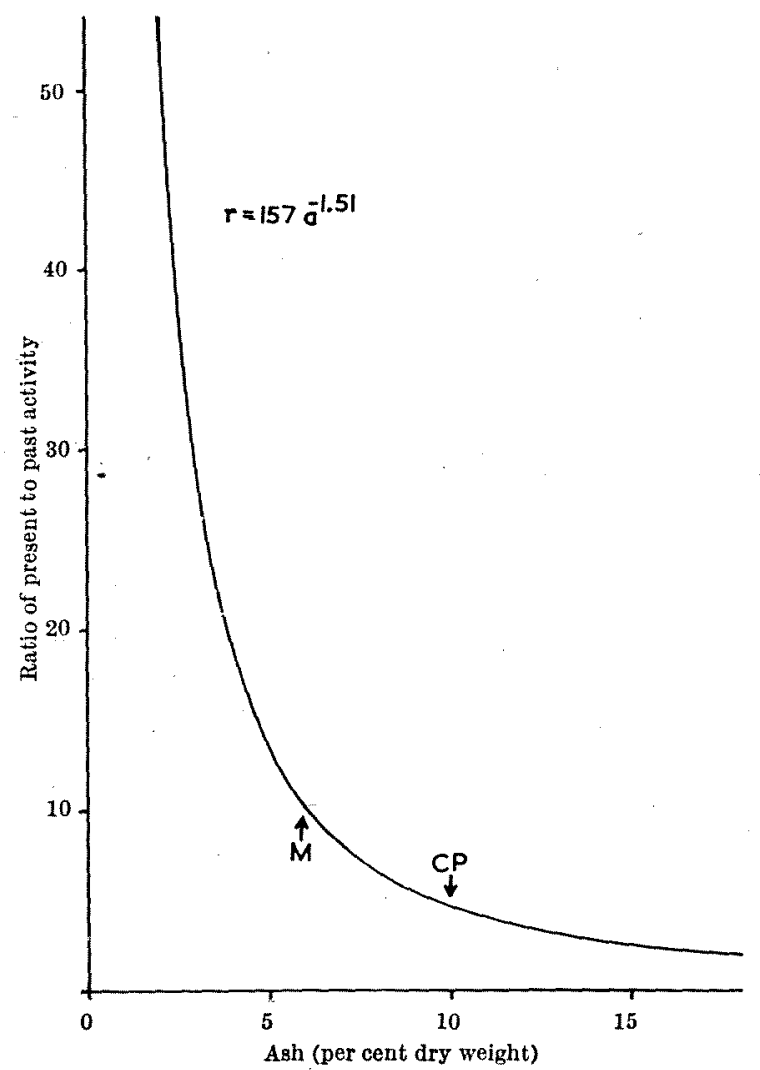

Fig. 2. Ratio of present to past radioactivity in plants of different ash content. In the equation $r$ represents ratio and $a$ ash percentage

various parts of the Lake District, and two near Garrigill and Malham in the Pennines. In addition, eleven stream and lake waters were analysed. Twenty-seven herbarium specimens of wild plants collected in the decade prior to 1947 were also examined. Their activity, due to long-lived natural isotopes, can be taken as little lower than when collected.

The plants were dried at $105-110^{\circ} \mathrm{C}$. and ashed at bright red heat; the waters were evaporated with nitric acid before ashing. Aliquots of about $50 \mathrm{mgm}$. ash were fixed in planchets with 'Celloidin' and tested within three days of collection for radioactivity, in a lead tower with a $C V 2139$ counter tube (end-window weight, $\left.2 \cdot 3 \mathrm{mgm} . / \mathrm{cm}^{2}\right)$. At least 1,000 counts 
were recorded for each sample on a 'Panax 44A' scaler. Background counts, averaging 8 per min., were measured daily and subtracted from those shown in Fig. I. No correction for self-absorption was applied, nor were the isotopes involved identified. The results merely give an arbitrary comparison of total activity in different plants.

The count-rates of plant ashes were closely related to the mineral content of the species. The correlation coefficients $(r)$ for logarithms of the rate of counting and percentage ash were -0.82 for the species collected in 1958 and -0.66 for the herbarium specimens. The logarithmic regressions of rate of counting upon percentage ash are shown arithmetically in Fig. 1, and it is clear that plants of low ash content now exhibit very much more radioactivity than those with a large mineral intake. This is true whether activity is calculated per unit of ash or of dry matter, and is to be expected since the plants with low ash generally grew on the more acid soils, where radioactive fall-out must account for a greater proportion of the soluble or adsorbed elements available to the vegetation. The cultivated plants, growing on the better soils, averaged 10 per cent ash as against a general mean of 6 per cent.

It is of interest to compare present count-rates with those prior to the nuclear era, and this has been done in Fig. 2, where the ratio of present to past activity is plotted against percentage ash. Evidently the activity of plants low in ash has increased up to fifty-fold over the past decade. The increase averages ten-fold for all plants, and declines to as little as two-fold in plants of high ash content on the best soils.

As an estimate of ability to accumulate radioactive materials, the ratio of count-rates of plant ash to those of ash from natural waters has been calculated. The concentration factor is 23 .

Concerning geographical distribution of fall-out, no pattern could be discerned in the rates of counting of Sphagnum papillosum from different parts of the Lake District and Pennines, though the typical decline with increasing ash (range shown in Fig. 1) was observed. The Windscale accident therefore appears to have contributed little to the activity measured. The decline in the rate of counting recorded for three Sphagnum samples over one month averaged about one-quarter of the original. Presumably the radioactivity of present vegetation is largely due to fall-out from nuclear explosions.

The biological significance of these results lies in the indication that plants which have a low mineral 
intake and grow on extremely acid soils accumulate radioactive fall-out to an extraordinary degree. The high concentration of strontium-90 in bones of upland sheep $^{1}$ may well be due in part to their reliance on such plants for fodder, especially in hard times.

EVILLE GoRHAM

Freshwater Biological Association,

Ambleside, Westmorland. April 8.

aryant, F. J., Chamberlain, A. C., Morgan, A., and Spicer; G. S. Atomic Energy Res. Estab., $\dot{H} P / R 2353$ (1957). 